\title{
Vascular remodeling as a biologic principle: Is the ulnar artery an exception?
}

Hendrick B. Barner, MD

See related article on page 9 .

From the Division of Cardiothoracic Surgery, Washington University School of Medicine and Forest Park Hospital, St Louis, Mo.

Received for publication March 4, 2005; accepted for publication March 14, 2005.

Address for reprints: Hendrick B. Barner, MD, 6125 Clayton Ave, Ste 430, St Louis, MO 63139 (E-mail: Hendrick.Barner@ forestparkhospital.com).

J Thorac Cardiovasc Surg 2005;130:7-8

$0022-5223 / \$ 30.00$

Copyright (c) 2005 by The American Association for Thoracic Surgery

doi:10.1016/j.jtcvs.2005.03.015
$\mathrm{A}$ ccumulating experience with the radial artery as a coronary bypass conduit has revealed limitations and some advantages. A report in this issue of the Journal is a flag that suggests a late potential complication of radial artery harvest, namely accelerated arteriosclerosis caused by hemodynamic stress in the remaining ulnar artery. ${ }^{1}$

To better understand this issue, it is important to examine the available information about the aging of small- and medium-sized arteries in an environment of risk factors for arterial disease, including altered flow. In the 1970s, some predicted that the internal thoracic artery (ITA) would develop accelerated arteriosclerosis because of the stressful nature of the coronary circulation, when in fact this was true of the saphenous vein.

Because not much data are available on the ulnar artery, it is necessary to extrapolate observations from other arteries to the ulnar artery, particularly from the radial artery, which is similar with regard to size, vascular bed, microanatomy, and location in the arterial tree.

Native ulnar artery flow varies with its size and that of its counterpart, the radial artery. Overall, in situ flow was $46 \%$ greater in the radial artery, but flow was similar in $26.5 \%$, greater in $56.9 \%$, and less in $16.6 \%$ in 211 nondominant arms assessed for hemodialysis access. ${ }^{2}$

Microscopic assessment of the distal radial artery revealed intimal hyperplasia (type B arteriosclerosis) in $94 \%$ and $69 \%$ of ITAs $(\mathrm{n}=110$ pairs), with type A arteriosclerosis (atherosclerosis) in $5.3 \%$ and $0.7 \%$, respectively, in patients having use of these arteries for coronary bypass. ${ }^{3}$ Radial arteries undergoing biopsy at the time of construction of fistulas for hemodialysis access had a $76 \%$ incidence $(\mathrm{n}=$ 59) of intimal hyperplasia without the presence of type A arteriosclerosis. ${ }^{4}$ Thus intimal hyperplasia is prevalent in the radial artery and also the ITA on the basis of histologic criteria and is associated with increased age, diabetes, peripheral vascular disease, and smoking. ${ }^{3,4}$

Arteries respond to an acute increase in flow with vasodilatation (10\%-15\% increase in diameter) and to chronic changes in flow caused by remodeling, which has been documented in animals and human subjects. ${ }^{5}$ Because the radial artery and ITA remodel to a comparable degree, it is evident that type B arteriosclerosis does not substantially affect remodeling. Blood flow changes in arterial conduits are modest when grafted (coronary) flow is compared with in situ flow. When the radial artery is used as a dialysis fistula or shunt, the flow increase can be many-fold.

More specifically, flow in the in situ ITA is in the range of 15 to $20 \mathrm{~mL} / \mathrm{min}$, and as a coronary graft, flow is 47 to $60 \mathrm{~mL} / \mathrm{min}$ for a flow ratio of 3.0. ${ }^{6,7}$ Radial artery flow in situ is 18 to $22 \mathrm{~mL} / \mathrm{min}^{8,9}$ and increases similarly to ITA flow for a single bypass, but when used sequentially, basal flow is 88 to $93 \mathrm{~mL} / \mathrm{min}^{7,10}$ Coronary flow reserve (adenosine vasodilation) is 2.5 to 2.8 six months postoperatively for left ITA-right ITA or left ITA-radial artery T grafts with peak flows of 140 and 150 $\mathrm{mL} / \mathrm{min}$, respectively, which represents a flow reserve of 6.0 over in situ flow. ${ }^{11}$ When coronary grafted radial artery flow was enhanced with infusions of nicardipine or nitroglycerin with simultaneous increase of the systolic blood pressure by $25 \%$ and $31 \%$, respectively, with phenylephrine, radial artery flow increased to 149 and $172 \mathrm{~mL} / \mathrm{min}$, respectively, for a flow reserve of 7.5 and 9.0 over in situ flow. ${ }^{10}$ 
In radial artery dialysis fistulas studied at 10, 40, and 100 days postoperatively, radial artery flow increased from 18 $\mathrm{mL} / \mathrm{min}$ to 329,476 , and $583 \mathrm{~mL} / \mathrm{min}$ at each interval (a final flow reserve of 32), respectively, whereas radial artery lumen diameter increased from 2.4 to $3.7,4.1$, and $4.4 \mathrm{~mm}$ over 100 days. ${ }^{9}$ Although mean wall shear stress increased from 6 to 33, 37, and 39 dynes $/ \mathrm{cm}^{2}$ at each interval, respectively, the peak wall shear stress increased from 45 to 54 , 62 , and 69 dynes $/ \mathrm{cm}^{2}$ (the increase in peak shear stress after day 10 was related to the increase in hematocrit value from erythropoetin), and this suggests that arterial diameter adjusts to normalize peak wall shear stress rather than mean wall shear stress. ${ }^{9,12}$ When dialysis fistulas were studied at a mean of 7 years, radial artery flow had increased from the contralateral control of 22 to $126 \mathrm{~mL} / \mathrm{min}$ (a flow reserve of 5.6), whereas arterial internal diameter increased from 2.40 to $3.31 \mathrm{~mm}$, and wall thickness was unchanged from control value. ${ }^{8}$ The lesser flow and diameter increases were attributed to the greater age of the fistulas, with reduction in size caused by venous obstruction, which is the usual mode of failure for dialysis fistulas. It is apparent that dialysis fistula flow is many-fold greater than in situ basal flow or coronary conduit flow, but arterial wall thickening has not been described. ${ }^{8}$

With regard to ulnar artery flow after radial artery harvest, we can assume that if it was initially a balanced system, then basal flow would double to $40 \mathrm{~mL} / \mathrm{min}$, and if the radial artery was dominant, then ulnar flow might increase to 60 to $70 \mathrm{~mL} / \mathrm{min}$. Although trained skeletal muscle can increase its blood flow 10- to 20-fold, it is unlikely that patients having coronary bypass grafting would have highly trained forearm muscle, or if they did, it is likely that the muscle would be exercised for only brief intervals each day unless there was an occupational imperative. Thus the basal flow increase in the ulnar artery after radial artery harvest is not greatly different from that of the coronary grafted radial artery but much less than in the radial artery fistula. Peak flow demands of trained forearm muscle could exceed those of cardiac muscle, but with untrained muscle, ulnar flow could approximate that measured in the grafted radial artery with pharmacologic manipulation. ${ }^{10}$

Remodeling occurs in response to endothelial sensed changes in shear stress (likely peak shear stress) ${ }^{9,12}$ with return of shear stress to or near normal. The diameter change in the artery reflects the magnitude of flow change in the artery. Thus nonsignificant increase in ulnar artery diameter ${ }^{1}$ indicates a small flow increase, and an increased peak systolic velocity ${ }^{1}$ is inconsistent with observations on radial artery fistulas ${ }^{8,9,12}$ or other arteriovenous fistulas. ${ }^{5}$ The occurrence or progression of intimal thickening in the ulnar artery is surprising. Progressive intimal thickening has not been observed in the radial artery proximal to a dialysis fistula ${ }^{8}$ or the coronary grafted radial artery at 10 years ${ }^{13}$ and the grafted ITA at 20 years. ${ }^{14}$ Attributing this intimal thickening to increased ulnar flow is less plausible than its cause by other vasculopathic determinants, such as age, diabetes, peripheral vascular disease, and smoking. ${ }^{3,4}$ If this observation $^{1}$ is valid, then our concern must be extended to the conduits themselves, which are frequently afflicted before use.

At this point, there is a flag on the field, of which we must be cognizant. Whether it is to be colored red or green will be determined by future observations by the authors and ideally others.

\section{References}

1. Gaudino N, Serricchio N, Tondi P, Gerardino L, Di Giorgio A, Pola T, et al. Chronic compensatory increase in ulnar flow and accelerated atherosclerosis following radial artery removal for coronary bypass grafting. J Thorac Cardiovasc Surg. 2005;130:9-12.

2. Goldstein LJ, Gupta S. Use of the radial artery for hemodialysis access. Arch Surg. 2003;138:1130-4.

3. Ruengsakulrach P, Sinclair R, Komeda M, Ranan J, Gordon I, Buxton B. Comparative histopathology of radial artery versus internal thoracic artery and risk factors for development of intimal hyperplasia and atherosclerosis. Circulation. 1999;100(suppl II):II139-44.

4. Kim Y, Song HC, Yoon SA, Yang CW, Kim NNI, Choy YJ, et al. Pre-existing intimal hyperplasia of radial artery is associated with early failure of radiocephalic arterial venous fistula and hemodialysis patients. Am J Kidney Dis. 2003;41:422-8.

5. Barner HB. Remodeling of arterial conduits in coronary grafting. Ann Thorac Surg. 2002;73:1341-5.

6. D'Ancona G, Hargrove M, Hinchion J, Ramesh BC, Chughtai JZ, Antrum MM, et al. Coronary grafts flow and cardiac patient modalities: how to improve perioperative myocardial infusion. Eur J Cardiothorac Surg. 2004;26:85-8.

7. Affleck BG, Barner HB, Bailey MS, Perry L, Manniar H, Prasad SM, et al. Flow dynamics of the internal thoracic and radial artery T-graft. Ann Thorac Surg. 2004;78:1290-4.

8. Girerd X, London G, Boutouyrie B, Mourad J-J, Safar M, Laurent S. Remodeling of the radial artery in response to a chronic increase in shear stress. Hypertension. 1996;27:799-803.

9. Ene-Iordazhe B, Mosconi L, Amtiga L, Bruno S, Anghileri A. Radial artery remodeling in response to shear stress increase within arterial venous fistula for hemodialysis access. Endothelium. 2003;10:95-102.

10. Skubas M, Barner HB, Apostilidou I, Lappas DG. Phenylephrine increases blood flow in the radial artery used as a coronary bypass conduit. J Thorac Cardiovasc Surg. In press.

11. Wendler O, Hennen B, Markwirth T, Koenig J, Tscholl D, Huang Q. $\mathrm{T}$-grafts with the right internal thoracic artery to left internal thoracic artery versus left internal thoracic artery and radial artery: flow dynamics in the internal thoracic artery mainstem. $J$ Thorac Cardiovasc Surg. 1999;118:841-8.

12. Dammers R, Tordoir JHM, Welten JTHJ, Kitslaar PJEHM, Hoeks APG. The effect of chronic flow changes on brachial artery diameter and shear stress in arterial venous fistulas for hemodialysis. Int J Artif Organs. 2002;25:124-8.

13. Possati G, Gaudino N, Prati F, Alessandrini F, Trani C, Glieca F, et al. Long-term results of the radial artery used for myocardial revascularization. Circulation. 2003;108:1350-4.

14. Barner HB, Barnett N. Fifteen to twenty-one year angiographic assessment of internal thoracic artery as a bypass conduit. Ann Thorac Surg. 1994;57:1526-8. 